Article

\title{
State Health Insurance Benefit Mandates and Health Care Affordability
}

\author{
James Bailey $\mathbb{D}$
}

check for updates

Citation: Bailey, James. 2022. State Health Insurance Benefit Mandates and Health Care Affordability. Journal of Risk and Financial Management 15: 84. https://doi.org/ $10.3390 /$ jrfm15020084

Academic Editors: Thanasis Stengos and Shigeyuki Hamori

Received: 4 December 2021

Accepted: 14 February 2022

Published: 17 February 2022

Publisher's Note: MDPI stays neutral with regard to jurisdictional claims in published maps and institutional affiliations.

Copyright: (c) 2022 by the author. Licensee MDPI, Basel, Switzerland. This article is an open access article distributed under the terms and conditions of the Creative Commons Attribution (CC BY) license (https:// creativecommons.org/licenses/by/ $4.0 /)$.
Department of Economics, Providence College, 1 Cunningham Sq, Providence, RI 02918, USA;

jbailey6@providence.edu

\begin{abstract}
Every US state requires private health insurers to cover certain conditions, treatments, and providers. These benefit mandates were rare as recently as the 1960s, but the average state now has more than forty. These mandates are intended to promote the affordability of necessary health care. This study aims to determine the extent to which benefit mandates succeed at this goal. Using fixed effects and difference-in-difference research designs with data from the restricted Medical Expenditure Panel Survey-Household Component (MEPS-HC), it provides the first empirical estimates of how health insurance benefit mandates affect out-of-pocket costs and total spending on health care. Both strategies find that mandates significantly reduce out-of-pocket spending, but they are divided on whether mandates also reduce overall health care spending and spending by private insurers.
\end{abstract}

Keywords: benefit mandates; out of pocket spending; health care affordability; Medical Expenditure Panel Survey

\section{Introduction}

Much of US health care policy is focused on expanding access to health care, and on making health insurance and health care more affordable. To this end, US states mandate that private health insurance plans cover certain conditions, treatments, and providers. Since the 1960s, the average state has gone from mandating fewer than one specific health insurance benefit to more than 40 today (Laudicina et al. 2013), a trend recently strengthened by the Affordable Care Act's (ACA) Essential Health Benefits provision. Common mandates include requirements to cover treatments for autism, alcoholism, and diabetes, and requirements to cover providers such as chiropractors, dentists, or psychologists.

If a state mandates that health insurance plans must cover a new treatment, such as autism therapy, it would seem to follow that the therapy should become more accessible and more affordable. This is certainly a major goal of state legislatures when they pass such mandates (Bellows et al. 2006). However, researchers have pointed out a number of ways in which the effect of health insurance benefit mandates on the affordability of health care is ambiguous and possibly negative, which could completely undermine the policy goal. This article is the first to test the hypotheses that health insurance benefit mandates reduce out-of-pocket health care spending by households, increase spending by private insurers, and increase overal health care spending.

\section{Literature Review}

A major goal of health insurance is to reduce the risk of large, unexpected out-ofpocket health costs. Evidence shows that health insurance typically succeeds at this goal. When policy changes, such as expanded Medicaid eligibility, lead new people to be covered by health insurance, their out-of-pocket health spending goes down (Barcellos and Jacobson 2015; Blascak and Mikhed 2019; Finkelstein et al. 2019; Gotanda et al. 2020). Yet how do mandated benefits that aim to expand what types of care existing health insurance covers affect out-of-pocket costs? There is no direct evidence, and the indirect evidence provides reason to think mandated benefits might not succeed in reducing out-of-pocket costs. 
Mandated benefits make insurance costlier to provide, which may lead insurers to increase premiums (Kowalski et al. 2008; LaPierre et al. 2009; Bailey 2014a; Depew and Bailey 2015). These higher costs, largely covered by employers, may lead them to reduce wages (Summers 1989; Gruber 1994a; Kaestner and Simon 2002; Antwi and Maclean 2017), increase the employee contribution to premiums (Bailey and Blascak 2016), discriminate against potential employees who have higher expected health costs (Gruber 1994a; Lahey 2012; Bailey 2013, 2014b), or take advantage of loopholes to avoid state mandates (Bailey and Webber 2018). Taken together, these reactions may decrease the overall rate of health insurance coverage (Jensen and Morrisey 1999; Finkelstein 2004; van der Goes et al. 2011).

As Gruber and Levy (2009) aptly stated, "A standard tradeoff arises here: mandating benefits will raise insurance prices, but the mandated benefits may not be fully valued by the insured. Therefore, as a result of the mandated benefits, those who remain insured have more comprehensive insurance, but some who do not value the mandated benefits may drop insurance altogether and end up facing greater risks". However, the practical significance of this tradeoff is an empirical question that has yet to be answered; no previous research has evaluated the effect of benefit mandates on out-of-pocket costs. This article aims to determine whether benefit mandates have in fact met their goal of protecting households from medical expenditure risk. This knowledge will aid state policymakers as they choose whether to enact further mandates and consider how to implement the ACA Essential Health Benefits provisions (Weiner and Colameco 2014).

\section{Mandates and Health Spending}

While previous research identified this tradeoff and has documented many specific ways in which the reactions of insurers and employers at least partly undermine the effectiveness of mandates, it remains unclear whether the net effect of mandates is to increase or to reduce the affordability of health care. Two key pieces of information needed to fully evaluate the effect of mandates have been missing: their effect on out-of-pocket healthcare spending and on overall healthcare spending. We must understand these outcomes in order to quantify the overall costs and benefits of mandates.

The mechanism by which mandates are expected to make care more affordable is by reducing out-of-pocket costs. If patients have been spending directly out-of-pocket on health care because it is not covered by insurance, then when a state mandate causes insurers to begin covering that care, we would generally expect out-of-pocket spending on that care to fall dramatically for insured patients. This has been found to be the case for the one mandate where out-of-pocket spending has been studied, mental health parity (Barry et al. 2006). To date, however, no previous study has measured whether state benefit mandates in general reduce out-of-pocket spending.

In this project, I evaluate the net effect of mandates on health care affordability using data on out-of-pocket and overall health care spending from the Medical Expenditure Panel Survey-Household Component (MEPS-HC). The MEPS-HC surveys approximately 30,000 households each year and collects extensive information on demographics, health status, health insurance, and health expenditures. Out-of-pocket costs are an important outcome in their own right for patients and policymakers. Knowing how state health insurance benefit mandates affect out-of-pocket costs is also crucial for evaluating mandates more broadly. Reducing out-of-pocket costs is a necessary condition for mandates to have positive effects on the affordability of care.

Figure 1 shows that out-of-pocket spending nationally has generally risen over time along with the average number of state mandates, but our regression analysis using individual- and state-level data suggests that if mandates have any causal effect it is to reduce out-of-pocket spending. In the next section, I consider more fully how mandates might affect out-of-pocket and overall health spending. 


\section{Mandates and Out-of-Pocket Spending}

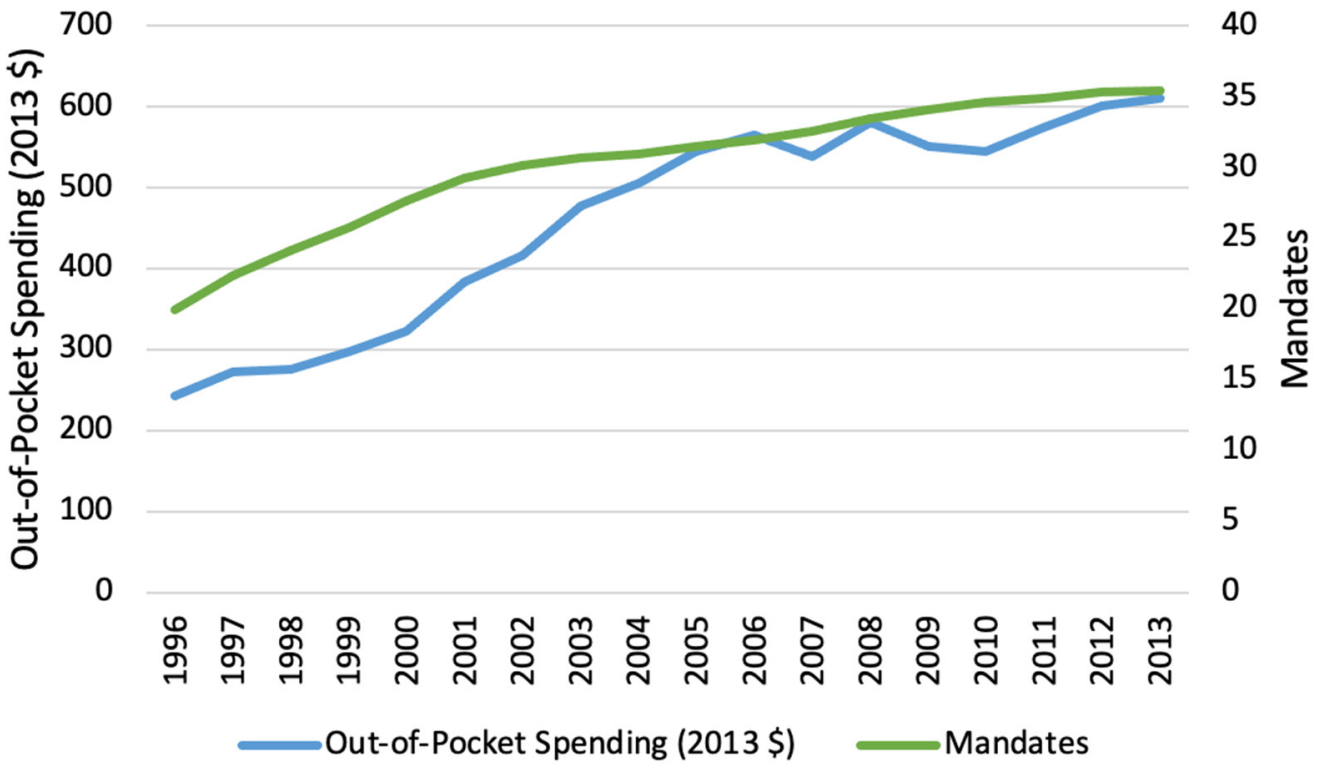

Figure 1. Mandates and out-of-pocket spending. Source: author calculations using mandate data from Laudicina et al. (2013) and spending data from the public version of MEPS-HC.

\section{Affordability Framework}

If mandates reduce household medical expenditure risk and promote affordability, we would expect them to work by reducing out-of-pocket spending on mandated services, being paid for by increased premiums and/or reduced insurer profits. If mandates are not working, we would expect to observe either that they are non-binding, with no effect on out-of-pocket spending on mandated services, or that they do reduce out-of-pocket costs of mandated services but that negative reactions (e.g., rising deductibles or coinsurance, insurers ceasing to cover non-mandated services, employers or individuals dropping coverage in response to rising premiums) prevent this from translating into more affordable care or more comprehensive insurance overall. I will assess how changes along many such margins together affect health care affordability, taking care to distinguish between its effect on average health care spending and its effect on risk reduction through insurance coverage.

Figure 2 categorizes the main possible effects of mandates. The first-stage effect of mandates is that they actually lead insurers to cover services they previously did not; if mandates are non-binding we would not expect any follow-on effects. Presuming that mandates are at least sometimes binding, as seems likely given that the literature has often found follow-on effects, we can then categorize those effects.

The left branch illustrates the effect that policymakers likely hope for: the mandate leads insurers to cover a service they otherwise would not, so that insured patients who use the service now pay less out-of-pocket; barring any countervailing effects, this reduction in out-of-pocketing spending leads to lower overall health spending by households and reduces their risk of suddenly incurring a large expense. This could be achieved if the mandate does not increase insurer costs, or if insurers do not pass cost increases on to patients.

The center branch illustrates ways in which the mandate could lead to increased average health spending by households, though without directly increasing their risk of large unexpected out-of-pocket costs. These are primarily ways that insurers, or employers offering insurance, could attempt to pass on the cost of the mandate to households: higher premiums or employee contributions to premiums. It also includes the possibility of moral hazard: households who did not use the service before the mandate begin to use it after it is covered by insurance. Even though they only pay a fraction of the cost of the service, 
their observed spending still rises because they now pay co-pays where previously they paid (and received) nothing.
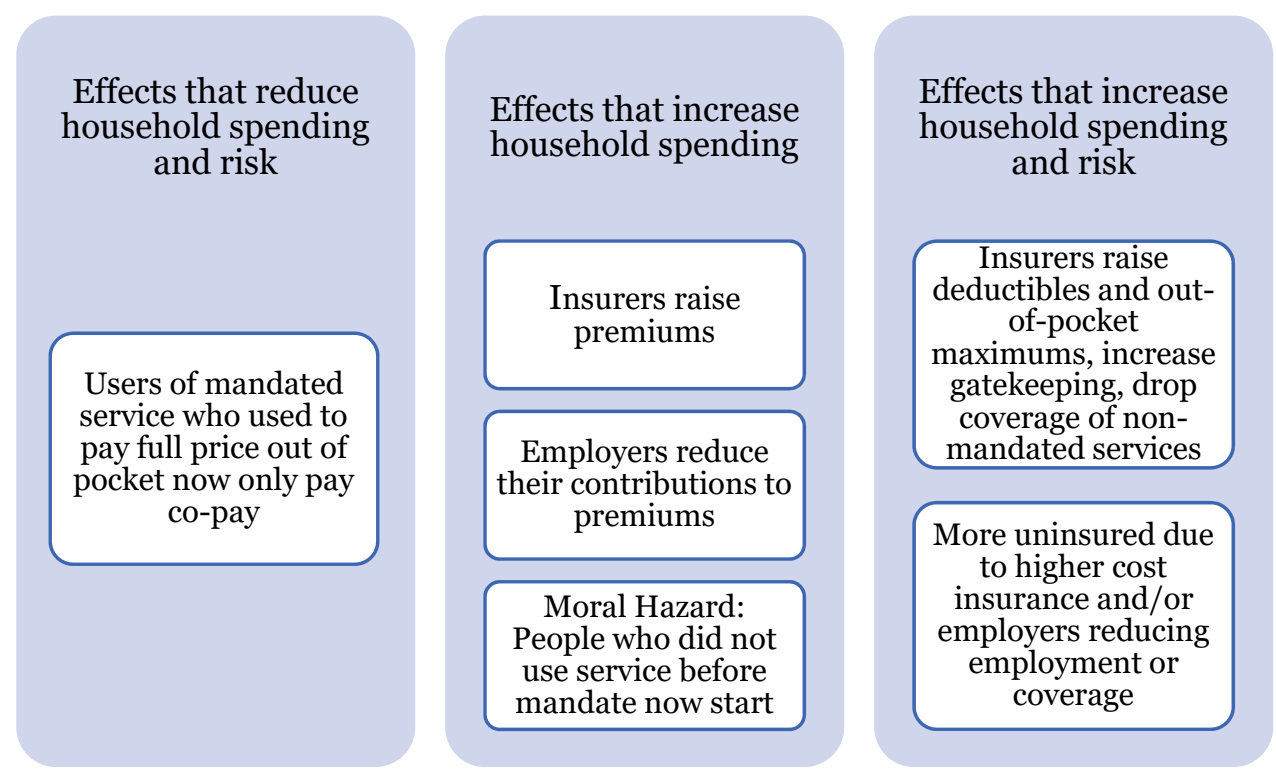

Figure 2. Effects of insurers covering a mandated service. Source: Created by author.

The right branch illustrates ways in which the mandate could lead households to take on more risk of unexpected out-of-pocket costs while also likely increasing average health spending. Insurers could lower the quality of their coverage by raising deductibles and out-of-pocket maximums or by reducing coverage of non-mandated services; this would lead to higher out-of-pocket spending and more risk for households. Finally, the sum of all these attempts to pass on the cost of the mandate to households could lead households to choose not to purchase insurance at all, or the higher cost of insurance could lead employers to reduce employment or drop insurance coverage.

The previous literature has tried to evaluate the extent to which mandates cause some of these costly countervailing effects. However, previous work has not attempted to evaluate whether mandates have benefits that exceed their costs. Most papers on mandates only attempt to quantify the extent of one or two of the costs described above. However, showing that one hypothesized cost is zero does not imply mandates are a good policy, and showing that one hypothesized cost is high does not imply mandates are a bad policy. To fully evaluate the policy, we either need to complete the arduous work of measuring all costs and benefits separately and summing them, or to find a few "sufficient statistics" that once measured can tell the full story themselves.

There has been one "sufficient statistic" for welfare analysis proposed in previous literature. In the Summers (1989) model, employers attempt to pass the costs of a mandate back to employees. If employees value the mandate at least as much as its cost, then this cost-shifting attempt succeeds at lowering wages; if employees value the mandate below its cost, the cost-shifting attempt leads to lower employment. Gruber (1994a) found that employees fully valued a mandate for maternity care, while Lahey (2012) and Bailey (2014b) found that employees did not fully value mandates for infertility treatment or prostate cancer screening, respectively. While this welfare analysis is valuable, it makes strong assumptions (e.g., competitive labor markets and perfect information), can only be applied to employer-sponsored insurance, and only tracks some of the margins of adjustment.

I propose a new set of sufficient statistics, as shown in Figure 3: out-of-pocket health care spending and overall health care spending (including out-of-pocket spending and premiums). Mandates could move these either up or down, and knowing which direction each moves allows us to characterize the net effect of the mandate. 


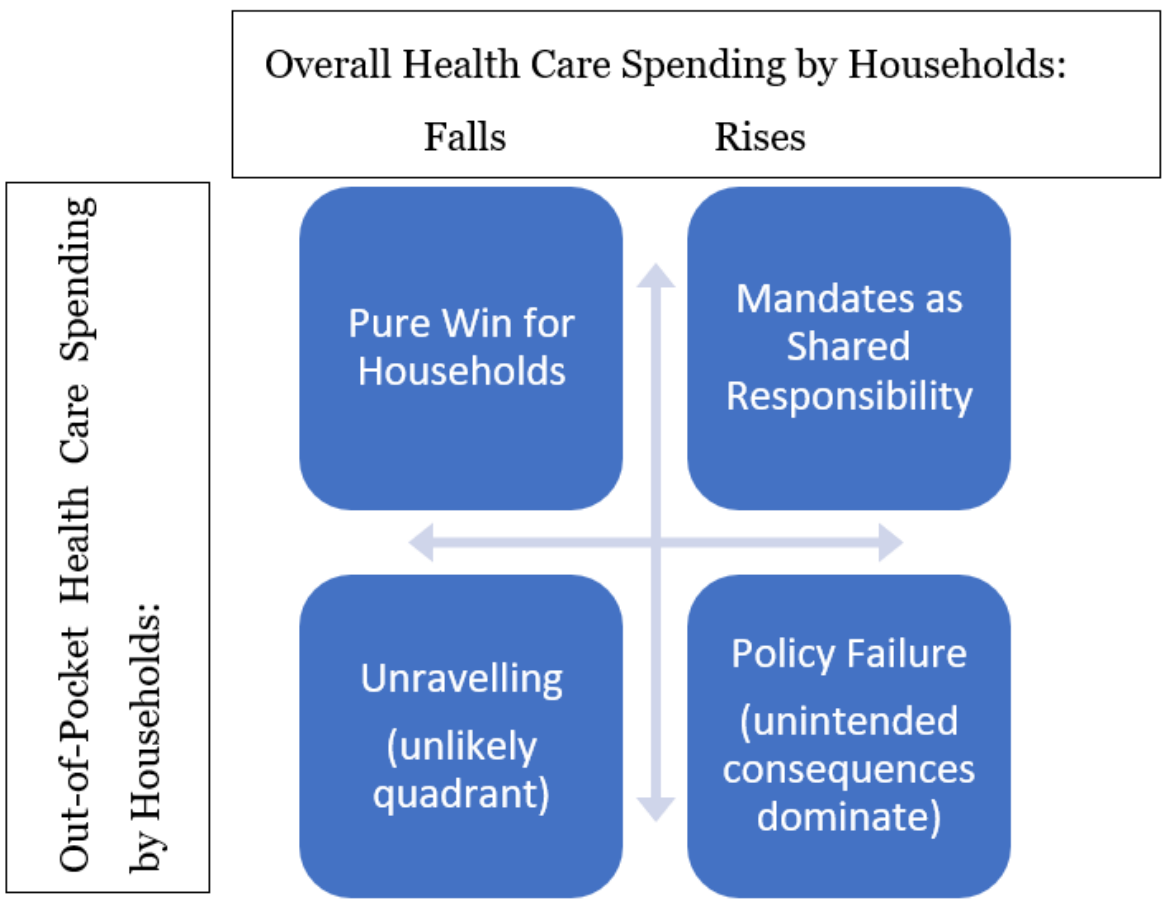

Figure 3. Potential effect of mandated benefits on out-of-pocket and overall health care spending. Source: created by author.

The top left quadrant of the figure shows the case where out-of-pocket and overall spending both fall. In this case, mandates caused a service to be covered, which led households who use the service to pay less out-of-pocket and overall; the negative countervailing effects were either zero or not enough to overwhelm this benefit. This is the case mandate advocates hope for, where the benefits of the mandate are clear and the costs are either non-existent, or small relative to benefits, or at least borne by insurers rather than households.

The top right quadrant shows the case where out-of-pocket costs fall but overall health spending by households rise. This case would occur if the benefit of the mandate reducing out-of-pocket costs is realized, but is more than offset by rising premiums, so that overall health care spending rises (premiums rise more than out-of-pocket spending falls). In this case, the benefit mandates take on the character of the ACA's "shared responsibility" mandate to buy insurance: households spend more overall on average but their risk is reduced as insurance pools it. This case is closest to a judgement call: households pay higher costs to get more insurance. This could be worth it if policymakers think that households systematically underestimate the need for insurance, or if adverse selection problems loom large.

The bottom two quadrants see out-of-pocket costs rise, undermining the case for mandates as a policy. Most likely this occurs if insurance quality falls, with insurers raising cost-sharing and reducing what they cover. Along with increases in premiums this could lead to increases in total health spending by households (bottom right quadrant). Alternatively, out-of-pocket spending could increase while total health spending falls (bottom left). This could indicate an unravelling of insurance markets, where rising premiums lead households or employers to drop insurance coverage entirely; this lack of coverage would increase out-of-pocket spending, but not by as much as spending on premiums fall. The demand for insurance would need to be quite elastic for the coverage-dropping effects to dominate, which is why I consider this quadrant unlikely. 


\subsection{Data Sources}

Data on state health insurance benefit mandates is available through 2013 from the Blue Cross Blue Shield Association (Laudicina et al. 2013). The data provide the total number of mandates in each state, as well as the exact mandated conditions, treatments, providers, or persons, and the year each mandate came into effect. These data have been used frequently in previous research on benefit mandates. Here I use it to create a variable that counts the total number of benefit mandates in effect in each state in each year 1996-2013.

The MEPS-HC provides the other key variables. Since 1996, the Agency for Healthcare Research and Quality has conducted the MEPS-HC annually by surveying approximately 30,000 households each year. They collect data on out-of-pocket health care expenditures as well as insurance coverage, demographics, and medical conditions. For privacy reasons, the public MEPS-HC does not include geographic information, so I use the restricted MEPS-HC that includes each respondent's state of residence, which allows me to merge in the state-level data on mandates. The MEPS-HC provides specific detail for many variables, breaking down expenditures both by source (e.g., out-of-pocket, Medicare, Medicaid, private insurance) and by type of care (e.g., hospital, office-based, prescription drug, dental). I adjust all expenditure variables for inflation in all regressions, reporting all results in 2012 dollars. The individual-level demographic control variables used are age (indicator variables for each year of age), gender, race (Black or Asian), ethnicity (Hispanic), education (indicators for high school degree and college degree), and health status (indicators for self-reported health that is good/very good and fair/poor, excellent health is the omitted category).

\subsection{Econometric Strategies}

\subsubsection{Fixed Effects}

The primary econometric approaches will be fixed effects and difference-in-difference, similar to most recent work on mandates. The initial baseline fixed effects specification is:

$$
\text { lnSpending }_{\text {ist }}=\beta_{1} \times \text { Mandates }_{\text {st }-1}+\beta_{2} \times X_{\text {ist }}+\beta_{3} \times \theta_{\mathrm{s}}+\beta_{4} \times \tau_{\mathrm{t}}+\varepsilon_{\text {ist }}
$$

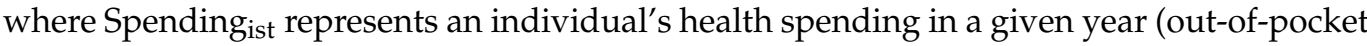
or total, depending on the regression), Mandates $_{\mathrm{st}-1}$ is a count of health insurance benefit mandates in place in the individual's state in the previous year, $X_{i s t}$ is a vector of individuallevel controls (age, gender, race, ethnicity, education, and health status), and $\theta_{\mathrm{s}}$ and $\tau_{\mathrm{t}}$ represent state and year fixed effects.

Endogeneity is certainly a significant concern, as states do not simply pass mandates at random. Among the many political and policy considerations that could influence the passage of mandates, one is particularly concerning: mandates could be passed in response to changes in out-of-pocket costs. For instance, rising out-of-pocket costs could spur patients or providers to lobby for a mandate that insurance cover them. If costs continued to rise after the mandate, the estimation strategy described above might estimate that mandates increase out-of-pocket costs even if they have no effect on costs or slightly reduce them. To some extent this issue could be tested for directly and controlled for using state-specific time trends. However, a better solution is to identify a control group that is subject to the same conditions before the mandate but that is not covered by the mandate. This group can be used as part of difference-in-difference estimation to more accurately identify the causal effect of the mandate.

\subsubsection{Difference-in-Difference}

The difference-in-difference strategy takes advantage of the fact that benefit mandates do not apply to everyone, but only to private insurance companies and those whom they cover. State mandates by their nature do not directly affect the uninsured, and due to federal pre-emption do not affect Medicare, Medicaid, or self-insured employer plans. Each of these could therefore provide a control group for those covered by the mandate, 
though we must be careful to select treatment and control groups that are similar enough to provide an appropriate match. For instance, Medicare recipients are on average older and might be expected to have different trends in out-of-pocket costs from privately insured individuals generally.

The most appropriate control group available is self-insured plans, as these are also private and cover a population most similar in income, age, and employment to those with non-mandate-exempt private plans. While MEPS-HC does not track which employer plans are self-insured, they do track a reasonable proxy: employer size. It is rare for firms with fewer than 50 employees to self-insure, and rare for firms with more than 50 employees not to. Because self-insured plans are exempt from mandates, we should expect mandates to have much larger effects on employees of small firms than those of large firms; previous work has found this to be the case (Bailey 2014a).

$\operatorname{lnSpending}_{\text {ist }}=\beta_{1} \times$ Mandates $_{\text {st }-1}+\beta_{2} \times$ SmallFirm $_{\text {ist }}+\beta_{3} \times$ Mandates $_{\text {st }-1} \times$ SmallFirm $_{\text {ist }}+\beta_{4} \times X_{\text {ist }}+\beta_{5} \times \theta_{\mathrm{s}}+\beta_{6} \times \tau_{\mathrm{t}}+\varepsilon_{\text {ist }}$

where $\beta_{3}$, the coefficient of interest, measures the effect of mandates on the out-of-pocket spending of employees of small firms. $X_{i t}$ is a vector of individual-level controls (such as age, race, and health status), and $\theta_{\mathrm{s}}$ and $\tau_{\mathrm{t}}$ represent state and year fixed effects.

\section{Results}

Table 1 shows the results of the baseline regressions. Mandates are initially associated with significant declines in all types of spending. However, once controls are added, they are associated only with a $0.8 \%$ decrease in out-of-pocket spending, with no statistically significant effect on total health spending or spending by private insurance.

Table 1. Effect of benefit mandates on health care spending.

\begin{tabular}{ccccccc}
\hline $\begin{array}{c}\text { Dependent } \\
\text { Variable }\end{array}$ & $\begin{array}{c}\text { OOP } \\
\text { Spending }\end{array}$ & $\begin{array}{c}\text { OOP } \\
\text { Spending }\end{array}$ & $\begin{array}{c}\text { Total } \\
\text { Spending }\end{array}$ & $\begin{array}{c}\text { Total } \\
\text { Spending }\end{array}$ & $\begin{array}{c}\text { Private } \\
\text { Insurance } \\
\text { Spending }\end{array}$ & $\begin{array}{c}\text { Private } \\
\text { Insurance } \\
\text { Spending }\end{array}$ \\
\hline Total Mandates & $-0.034^{* * *}$ & $-0.008^{* *}$ & $-0.023^{* * *}$ & -0.005 & $-0.037^{* * *}$ & -0.001 \\
State FE & $(0.007)$ & $(0.003)$ & $(0.007)$ & $(0.005)$ & $(0.009)$ & $(0.005)$ \\
Year FE & $\mathrm{N}$ & $\mathrm{Y}$ & $\mathrm{N}$ & $\mathrm{Y}$ & $\mathrm{Y}$ & $\mathrm{N}$ \\
Individual & $\mathrm{N}$ & $\mathrm{Y}$ & $\mathrm{N}$ & $\mathrm{Y}$ & $\mathrm{N}$ & $\mathrm{Y}$ \\
Controls & $\mathrm{N}$ & $\mathrm{Y}$ & $\mathrm{N}$ & 0.24 & 0.01 & 0.21 \\
$\mathrm{R}^{2}$ & 0.01 & 0.31 & 0.01 & 315,176 & 315,723 & 315,176 \\
Observations & 315,723 & 315,176 & 315,723 & &
\end{tabular}

Notes: Robust standard errors clustered by state. ${ }^{* *} p<0.01^{* *} p<0.05$.

Table 2 shows the difference-in-difference results, where the negative effect remains statistically significant for all types of spending even once controls are added, showing a $0.9-1.0 \%$ drop in each type of spending.

Table 2. Difference-in-difference effect of benefit mandates on health care spending.

\begin{tabular}{cccc}
\hline Dependent Variable & OOP Spending & Total Spending & $\begin{array}{c}\text { Private Insurance } \\
\text { Spending }\end{array}$ \\
\hline Total Mandates $\times$ Small Firm & $-0.009 * * *$ & $-0.010^{* * *}$ & $-0.009 * * *$ \\
State FE & $(0.002)$ & $(0.002)$ & $(0.002)$ \\
Year FE & $\mathrm{Y}$ & $\mathrm{Y}$ & $\mathrm{Y}$ \\
Individual Controls & $\mathrm{Y}$ & $\mathrm{Y}$ & $\mathrm{Y}$ \\
$\mathrm{R}^{2}$ & $\mathrm{Y}$ & 0.23 & 0.24 \\
Observations & 0.24 & 129,318 & 282,313 \\
\hline
\end{tabular}

Notes: Robust standard errors clustered by state. ${ }^{* * *} p<0.01$. 
These results are puzzling. It is clear how mandates can reduce out-of-pocket spending: by making insurers cover treatments that were previously paid out-of-pocket. It is also clear how mandates can reduce spending by private insurance: making insurance coverage so expensive that small employers drop it entirely or dramatically reduce its quality. Yet it is not clear how both of these effects could happen together. If mandates shift costs from patients to insurers, how are insurers paying less? If mandates lead to less insurance or lower-quality insurance, how is out-of-pocket spending down? Mandates could be targeting preventative treatments that actually save money-but would it not have been in the interest of insurers to cover such treatments before they were required to? Perhaps not, if such investments only pay off over time and each insurer worries that patients are likely to switch insurers before the first insurer realizes the savings. Alternatively, this could work by reducing Rothschild and Stiglitz (1976)-style adverse selection cycles. Perhaps each insurer did not want to offer generous coverage even when doing so could save money on existing enrollees, because they worried about attracting particularly unhealthy enrollees.

\section{Conclusions}

Using fixed effects and difference-in-difference econometric strategies and restricted MEPS-HC data, I provide the first estimates of how health insurance benefit mandates affect out-of-pocket and overall health care spending. Both strategies find that mandates reduce out-of-pocket spending, while they are divided on whether mandates also reduce overall health care spending and spending by private insurers.

Simply summing the total number of state mandates in a given year has the drawback that we do not expect all mandates to have the same effect on costs. Some mandates target treatments, conditions, or providers that are common and/or expensive (e.g., dentists, chiropractors, autism therapy) and so might have large effects, while others would be expected to be have smaller effects due to covering inexpensive things and/or rare conditions (e.g., lead screening for children or wigs for cancer patients). There are two main alternatives to this simple summation. One is to create an index that weights mandates by their predicted costs, or to use only mandates actuarially predicted to have high costs, as in Gruber (1994b). Another is to study mandates individually. Studying single mandates would allow for superior identification strategies that better address concerns over endogeneity; but studying all of the 100+ mandates individually would be challenging, while focusing on a few may tell us little about the rest if the few studied are unrepresentative.

Another limitation of the data is that it does not include health insurance premiums. In the "affordability framework" I discuss, I am interested in households' overall spending on healthcare- including health insurance premiums. However, the "total health care spending" variable in MEPS includes spending BY health insurers on behalf of their enrollees, not the households' spending on premiums. Therefore, lower "total health spending" as measured by this variable does not necessarily indicate that health care is more affordable for households.

Due to these divided results and the limitations of the data and econometric strategies, I am unable to determine whether or not health insurance benefit mandates represent a win for households. Yet, while I cannot say for sure whether the benefits of these mandates exceed the costs, I can say that the benefits exist. Mandates on average do lead to lower out-of-pocket costs for households. Policymakers should weigh this benefit of mandates alongside the costs of mandates identified by the previous literature, such as higher premiums, as they consider whether to pass additional mandates or repeal previous ones.

Funding: This research received no external funding.

Data Availability Statement: Restrictions apply to the availability of these data. Data was obtained from AHRQ and are available to those who obtain permission from AHRQ here: https:/ / www.meps. ahrq.gov / mepsweb / data_stats/onsite_datacenter.jsp, (accessed on 16 January 2022). 


\begin{abstract}
Acknowledgments: Thanks to Dhaval Dave, Catherine Maclean, Dalila Alves, Eleanor Lewin, Juan Rojas, Anna Chorniy, AHRQ reviewers, and participants at the Association of Private Enterprise Education and American Society of Health Economists 2021 meetings for helpful comments. The research in this paper was conducted using the CFACT Data Center, and the support of AHRQ is acknowledged. The results and conclusions in this paper are those of the author and do not indicate concurrence by AHRQ or the Department of Health and Human Services.
\end{abstract}

Conflicts of Interest: The author has no conflict of interest to report.

\title{
References
}

Antwi, Yaa Akosa, and Catherine Maclean. 2017. State Health Insurance Mandates and Labor Market Outcomes: New Evidence on Old Questions. Bonn: IZA, Discussion Paper. No. 10578.

Bailey, James. 2013. Who pays for obesity? Evidence from health insurance benefit mandates. Economics Letters 121: 287-89. [CrossRef] Bailey, James. 2014a. The Effect of Health Insurance Benefit Mandates on Premiums. Eastern Economic Journal 40: 119-27. [CrossRef]

Bailey, James. 2014b. Who Pays the High Health Costs of Older Workers? Evidence from Prostate Cancer Screening Mandates. Applied Economics 46: 3931-41. [CrossRef]

Bailey, James, and Douglas Webber. 2018. Health Insurance Benefit Mandates and Firm Size Distribution. Journal of Risk and Insurance 85: 577-95. [CrossRef]

Bailey, James, and Nathan Blascak. 2016. The effect of state health insurance benefit mandates on premiums and employee contributions. Applied Economics Letters 23: 1042-6. [CrossRef]

Barcellos, Silvia Helena, and Mireille Jacobson. 2015. The effects of medicare on medical expenditure risk and financial strain. American Economic Journal: Economic Policy 7: 41-70. [CrossRef] [PubMed]

Barry, Colleen, Richard Frank, and Thomas McGuire. 2006. The Costs of Mental Health Parity: Still an Impediment? Health Affairs 25: 623-34. [CrossRef]

Bellows, Nicole M., Helen Ann Halpin, and Sara B. McMenamin. 2006. State-Mandated Benefit Review Laws. Health Services Research 41: 1104-23. [CrossRef]

Blascak, Nathan, and Slava Mikhed. 2019. Health Insurance and Young Adult Financial Distress. Federal Reserve Bank of Philadelphia Working Paper WP 19-54. Available online: https:/ / www.philadelphiafed.org/consumer-finance/consumer-credit/financialconsequences-of-health-insurance-evidence-from-the-acas-dependent-coverage-mandate (accessed on 16 January 2022 ).

Depew, Briggs, and James Bailey. 2015. Did the Affordable Care Act's dependent coverage mandate increase premiums? Journal of Health Economics 41: 1-14. [CrossRef]

Finkelstein, Amy. 2004. Minimum standards, insurance regulation and adverse selection: Evidence from the Medigap market. Journal of Public Economics 88: 2515-47. [CrossRef]

Finkelstein, Amy, Nathaniel Hendren, and Erzo F. P. Luttmer. 2019. The Value of Medicaid: Interpreting Results from the Oregon Health Insurance Experiment. Journal of Political Economy 127: 2836-74. [CrossRef] [PubMed]

Gotanda, Hiroshi, Ashish K. Jha, Gerald F. Kominski, and Yusuke Tsugawa. 2020. Out-of-pocket spending and financial burden among low income adults after Medicaid expansions in the United States: Quasi-experimental difference-in-difference study. BMJ 368: m40. [CrossRef] [PubMed]

Gruber, Jonathan. 1994a. The Incidence of Mandated Maternity Benefits. American Economic Review 84: 622-41.

Gruber, Jonathan. 1994b. State-Mandated Benefits and Employer-Provided Health Insurance. Journal of Public Economics 55: 433-64. [CrossRef]

Gruber, Jonathan, and Helen Levy. 2009. The Evolution of Medical Spending Risk. Journal of Economic Perspectives 23: 25-48. [CrossRef] [PubMed]

Jensen, Gail A., and Michael A. Morrisey. 1999. Employer-Sponsored Health Insurance and Mandated Benefit Laws. The Milbank Quarterly 77: 425-59. [CrossRef] [PubMed]

Kaestner, Robert, and Kosali I. Simon. 2002. Labor Market Consequences of State Health Insurance Regulation. Industrial and Labor Relations Review 56: 136-59. [CrossRef]

Kowalski, Amanda E., William J. Congdon, and Mark H. Showalter. 2008. State Health Insurance Regulations and the Price of High-Deductible Policies. Forum for Health Economics and Policy 11: 1-26. [CrossRef]

Lahey, Joanna N. 2012. The Efficiency of a Group-Specific Mandated Benefit Revisited: The Effect of Infertility Mandates. Journal of Policy Analysis and Management 31: 63-92. [CrossRef]

LaPierre, Tracey A., Christopher J. Conover, James W. Henderson, J. Allen Seward, and Beck A. Taylor. 2009. Estimating the Impact of State Health Insurance Mandates on Premium Costs in the Individual Market. Journal of Insurance Regulation 27 : 3-36.

Laudicina, Susan, Joan Gardner, and Kim Holland. 2013. State Legislative Healthcare and Insurance Issues. Technical Report. Chicago: Blue Cross and Blue Shield Association.

Rothschild, Michael, and Joseph Stiglitz. 1976. Equilibrium in Competitive Insurance Markets: An Essay on the Economics of Imperfect Information. The Quarterly Journal of Economics 90: 629-49. [CrossRef]

Summers, Lawrence H. 1989. Some Simple Economics of Mandated Benefits. American Economic Review 79: 177-83. 
van der Goes, David N., Justin Wang, and Katharine C. Wolchik. 2011. Effect of State Health Insurance Mandates on Employer-Provided Health Insurance. Eastern Economic Journal 37: 437-449. [CrossRef]

Weiner, Janet, and Christopher Colameco. 2014. Essential Health Benefits: 50-State Variations on a Theme. Technical Report. Princeton: Robert Wood Johnson Foundation. 